\title{
Hyperopic shift in refraction in adults with aging
}

\author{
David Goldblum • Annette Brugger • \\ Andreas Haselhoff • Stefanie Schmickler
}

Received: 26 June 2013 / Accepted: 8 July 2013 / Published online: 25 July 2013

(C) Springer-Verlag Berlin Heidelberg 2013

\section{Dear Editor}

We thank Lin Miao, Zhen-Yong Zhang and Zhi-Qiang Yu for their comments on our article Longitudinal change of refraction over at least 5 years in 15,000 patients [1]. In their letter, they discuss and hypothesize the causes for myopisation or hyperopic shift and aging.

As they mentioned, initial refraction is of interest for the probability of refractive change during aging, which is the reason why we did not only group our patients according to their initial age but also according to their initial refraction in each age group, which was illustrated in detail in figure 2 .

Myopic shift in younger patients is actually described as multifactorial, possibly involving a large number of genes of small effect, and major environmental factors [2]. These environmental factors include total time spent outdoors, light, and hyperopic defocus among others.
The aim of our study was not to add or clarify the causes of refractive changes, but merely to describe the probability of refractive change over time for an individual (starting at various ages and with different initial refractions), deducing this with data from a very large cohort of mainly European patients.

\section{References}

1. Goldblum D, Brugger A, Haselhoff A, Schmickler S (2013) Longitudinal change of refraction over at least 5 years in 15,000 patients. Graefes Arch Clin Exp Ophthalmol 251:1431-1436

2. Morgan IG, Ohno-Matsui K, Saw SM (2012) Myopia. Lancet 379(9827):1739-1748

D. Goldblum $(\bowtie) \cdot$ A. Brugger

Department of Ophthalmology, University Hospital Basel, University Basel, 4031 Basel, Switzerland

e-mail: goldblum@yahoo.com

D. Goldblum

e-mail: dgoldblum@uhbs.ch

A. Haselhoff · S. Schmickler

Augenärzte Gemeinschaftspraxis Ahaus-Gronau-Lingen,

48683 Ahaus, Germany 